NBER WORKING PAPER SERIES

ANIMAL SPIRITS IN A MONETARY MODEL

\author{
Roger E.A. Farmer \\ Konstantin Platonov \\ Working Paper 22136 \\ http://www.nber.org/papers/w22136 \\ NATIONAL BUREAU OF ECONOMIC RESEARCH \\ 1050 Massachusetts Avenue \\ Cambridge, MA 02138 \\ March 2016
}

We would like to thank Gauti Eggertsson for his discussion of our work at the Conference in Honor of Michael Woodford's Contributions to Economics, held at the Federal Reserve Bank of New York on May 19th and 20th of 2016. We also thank the participants at the conference and participants at the UCLA macro and international finance workshops. We have both benefited from conversations with Giovanni Nicolò. The views expressed herein are those of the authors and do not necessarily reflect the views of the National Bureau of Economic Research.

NBER working papers are circulated for discussion and comment purposes. They have not been peer-reviewed or been subject to the review by the NBER Board of Directors that accompanies official NBER publications.

(C) 2016 by Roger E.A. Farmer and Konstantin Platonov. All rights reserved. Short sections of text, not to exceed two paragraphs, may be quoted without explicit permission provided that full credit, including $\odot$ notice, is given to the source. 
Animal Spirits in a Monetary Model

Roger E.A. Farmer and Konstantin Platonov

NBER Working Paper No. 22136

March 2016, Revised February 2017

JEL No. E12,E3,E4

\begin{abstract}
$\underline{\text { ABSTRACT }}$
We propose a fresh way of thinking about the monetary transmission mechanism. By integrating Keynesian economics with general equilibrium theory in a new way, we provide an alternative model and an alternative narrative to New-Keynesian economics to explain how macroeconomic policy influences prices and employment. We develop a simple graphical apparatus, the IS-LMNAC framework, that can be used by policy makers to understand how policy affects the economy. A new element, the NAC curve, connects the interest rate to current and expected future values of the stock market and it explains how 'animal spirits' influence economic activity. Our framework provides a rich new approach to policy analysis that explains the short-run and long-run effects of policy, without the assumption that prices are prevented from moving by artificial barriers to price adjustment.
\end{abstract}

\author{
Roger E.A. Farmer \\ UCLA \\ Department of Economics \\ Box 951477 \\ Los Angeles, CA 90095-1477 \\ and NBER \\ rfarmer@econ.ucla.edu \\ Konstantin Platonov \\ University of California at Los Angeles \\ kplatonov@ucla.edu
}




\title{
Animal Spirits in a Monetary Model
}

\author{
By Roger E.A. Farmer and Konstantin Platonov*
}

We propose a fresh way of thinking about the monetary transmission mechanism. By integrating Keynesian economics with general equilibrium theory in a new way, we provide an alternative model and an alternative narrative to New-Keynesian economics to explain how macroeconomic policy influences prices and employment. We develop a simple graphical apparatus, the IS-LM-NAC framework, that can be used by policy makers to understand how policy affects the economy. A new element, the NAC curve, connects the interest rate to current and expected future values of the stock market and it explains how 'animal spirits' influence economic activity. Our framework provides a rich new approach to policy analysis that explains the short-run and long-run effects of policy, without the assumption that prices are prevented from moving by artificial barriers to price adjustment.

In the lead-up to the 2008 financial crisis, a consensus developed among academic macroeconomists that the problem of macroeconomic stability had been solved. According to that consensus, the New-Keynesian dynamic stochastic general equilibrium (DSGE) model provides a good first approximation to the way that monetary policy influences output, inflation and unemployment. In its simplest form, the NK model has three equations; a dynamic IS curve, a policy equation that describes how the central bank sets the interest rate, and a NewKeynesian Phillips curve. In its more elaborate form, the New-Keynesian DSGE model is reflected in work that builds on the medium scale DSGE model of Frank Smets and Raf Wouters (2007).

The NK model evolved from post-war economic theory in which the Keynesian economics of the General Theory, (Keynes, 1936), was grafted onto the microeconomics of Walrasian general equilibrium theory (Walras, 1899). Paul Samuelson, in the third edition of his undergraduate textbook, (Samuelson, 1955), referred to this hybrid theory as the 'neoclassical synthesis'. According to the neoclassical synthesis, the economy is Keynesian in the short-run, when not all wages and prices have adjusted to clear markets; it is classical in the long-run, when all wages and prices have adjusted to clear markets and the demands and supplies

\footnotetext{
* Farmer: Department of Economics, UCLA, rfarmer@econ.ucla.edu. Platonov: Department of Economics, UCLA, kplatonov@ucla.edu. We would like to thank Gauti Eggertsson for his discussion of our work at the Conference in Honor of Michael Woodford's Contributions to Economics, held at the Federal Reserve Bank of New York on May 19th and 20th of 2016. We also thank the participants at the conference and participants at the UCLA macro and international finance workshops. We have both benefited from conversations with Giovanni Nicolò.
} 
for all goods and for labor are equal. ${ }^{1}$

The neoclassical synthesis is still the main framework taught in economics textbooks, and, in the form of 'dynamic IS-LM analysis', it is used by policy makers to frame the way they think about the influence of changes in fiscal and monetary policy on economic activity. ${ }^{2}$ This paper proposes an alternative framework. Building on work by Roger Farmer (2010b) we integrate Keynesian economics with general equilibrium theory in a new way to demonstrate that low-income high-unemployment inefficient equilibria may be sustained in the long run. Our work displays two main differences from the New Keynesian model.

First, the steady state equilibria of our model display dynamic indeterminacy. For every steady state equilibrium, there are multiple dynamic paths, all of which converge to the same steady state. We use that property to explain how changes in the money supply may be associated with immediate changes in real economic activity without invoking artificial barriers to price change. ${ }^{3}$

Second, our model displays steady state indeterminacy. We adopt a labor search model in which the presence of externalties generates multiple steady state equilibria. Unlike classical search models we do not close the model by assuming that firms and workers bargain over the wage. ${ }^{4}$ Instead, as in Farmer (2010b; 2012a; 2016a), firms and workers take wages and prices as given and employment is determined by aggregate demand. We use that feature to explain why unemployment is highly persistent in the data. Persistent unemployment, in our model, represents potentially permanent deviations of the market equilibrium from the social optimum. ${ }^{5}$

To close our model, we assume that equilibrium is selected by 'animal spirits' and we model that idea with a belief function as in Farmer (1993, 2002, 2012c). We treat the belief function as a fundamental with the same methodological status as preferences and endowments and we study the implications of that assumption for the ability of monetary policy to influence inflation, output and unemployment.

\footnotetext{
${ }^{1}$ This characterization of the history of thought is drawn from Farmer (2010a) and elaborated on in Farmer (2016a).

${ }^{2}$ See, for example, Mankiw (2015).

${ }^{3}$ For earlier papers that invoke that idea see Farmer and Woodford (1984, 1997), Farmer (1991, 1993, 2002, 2000), Matheny (1998), and Benhabib and Farmer (2000). We prefer to avoid the assumption of menu costs (Mankiw, 1985) or price rigidity (Christiano et al., 2005; Smets and Wouters, 2007), because our reading of the evidence as surveyed by Klenow and Malin (2017), is that prices at the micro level are not sticky enough to explain the properties of monetary shocks in aggregate data. King et al. (1991); Beyer and Farmer (2007); Farmer (2012b) and Farmer (2015) find evidence of a unit root in the U.S. unemployment rate. Sticky-price models have difficulty generating enough persistence to understand this fact, as do models of the monetary transmission mechanism that assume sticky information (Mankiw and Reis, 2007) or rational inattention, (Sims, 2003). Our approach generates permanent equilibrium movements in the unemployment rate that are consistent with a unit root, or near unit root, in U.S. unemployment data.

${ }^{4}$ By classical search models, we mean the literature that builds on work by Peter Diamond, (1982), Dale Mortensen, (1970), and Chris Pissarides (1976).

${ }^{5}$ Olivier Blanchard and Lawrence Summers $(1986 ; 1987)$ attribute persistent unemployment to models that display hysteresis. Our model has that feature, but for different reasons than the explanation given by Blanchard and Summers. For a recent survey that explains the evolution of models of dynamic and steady state indeterminacy, see Farmer (2016b).
} 


\section{The Model}

We construct a two-period overlapping generations model. In every period there are two generations of representative households; the young and the old. The young inelastically supply one unit of labor, but, due to search frictions, a fraction of young individuals remain unemployed in any given period. We assume that there is perfect insurance within the household and that labor income is split between current consumption, interest bearing assets, and money balances.

Households hold money, physical capital and financial assets in the form of government bonds. Money is dominated in rate-of-return and is held for transaction purposes. We model this by assuming that real money balances yield utility as in Patinkin (1956). The old generation receives interest on capital and bonds and they sell assets to the young generation. We close the markets for physical capital and labor by assuming that there is one unit of non-reproducible capital and that the labor-force participation rate is constant and equal to one. We also assume that government bonds are in zero net supply.

There is a single good produced by a continuum of competitive firms. Firms rent capital from old generation individuals and hire young generation individuals. Hiring labor is subject to search frictions. Firms take prices and wages as given and they allocate a fraction of labor to recruiting. We assume that every worker allocated to recruiting can hire $q$ new workers, where $q$ is taken as given by firms but determined in equilibrium by the search technology. Every worker allocated to recruiting is one less worker allocated to production.

Search in the labor market generates multiple equilibria. To select equilibrium, we assume that economic agents form beliefs about the real value of their financial wealth using a belief function that is a primitive of our model. Our Keynesian search approach differs from the more usual assumption in the classical labor search literature where the equilibrium is pinned down by Nash bargaining over the real wage. ${ }^{6}$

Our model provides a microfoundation from the textbook Keynesian cross, in which the equilibrium level of output is determined by aggregate demand. Our labor market structure explains why firms are willing to produce any quantity of goods demanded, and our assumption that beliefs are fundamental determines aggregate demand. In our model, beliefs select an equilibrium and in that equilibrium, the unemployment rate may differ permanently from the social planning optimum.

\section{Aggregate Supply}

There is a continuum of competitive firms and we represent the labor and capital employed and output produced by each individual firm with the symbols $L_{t}, K_{t}$,

\footnotetext{
${ }^{6}$ Farmer (2016a, Chapter 7) distinguishes Keynesian search models, where employment is determined by aggregate demand, from classical search models, where employment is determined by Nash bargaining.
} 
and $Y_{t} \cdot{ }^{7}$ To refer to aggregate labor and aggregate output we use the symbols $\bar{L}_{t}$ and $\bar{Y}_{t}$. The variables $L_{t}, K_{t}$, and $Y_{t}$ are indexed by $j \in[0,1]$ where

$$
\bar{L}_{t}=\int_{j} L_{t}(j) d j, \quad \bar{K}_{t}=\int_{j} K_{t}(j) d j, \quad \text { and } \quad \bar{Y}_{t}=\int_{j} Y_{t}(j) d j .
$$

Since we assume that all firms make the same decisions it will always be true that $L_{t}(j)=L_{t}, K_{t}(j)=K_{t}$ and $Y_{t}(j)=Y_{t}$, hence, we will dispense with the subscript $j$ in the remainder of our exposition.

We assume that all workers work only in the first period of their life. A firm puts forward a production plan in which it proposes to allocate $X_{t}$ workers to production and $V_{t}$ workers to recruiting where

$$
L_{t}=X_{t}+V_{t}
$$

Output is given by the expression

$$
Y_{t}=K_{t}^{\alpha} X_{t}^{1-\alpha}
$$

and the total number of workers employed at the firm is equal to

$$
L_{t}=q_{t} V_{t}
$$

where the firm takes $q_{t}$ as given. Puting these pieces together, we may express the output of the firm as

$$
Y_{t}=K_{t}^{\alpha}\left[\left(1-\frac{1}{q_{t}}\right) L_{t}\right]^{1-\alpha} .
$$

The profit maximizing firm sets

$$
(1-\alpha) \frac{Y_{t}}{L_{t}}=\frac{W_{t}}{P_{t}} \quad \text { and } \quad \alpha \frac{Y_{t}}{K_{t}}=\frac{R_{t}}{P_{t}}
$$

where $P_{t}$ is the money price of goods, $W_{t}$ is the money wage and $R_{t}$ is the money rental rate of capital.

Notice that Equation (2) looks like a classical production function with one exception. The variable, $q_{t}$, which represents labor market tightness, influences total factor productivity. One may show that $q_{t}$ is greater than 1 in equilibrium. A low value of $q_{t}$ corresponds to a tight labor market in which firms must devote a large amount of resources to recruiting and in which productivity is low. A high value of $q_{t}$ corresponds to a loose labor market in which firms may devote a small amount of resources to recruiting and in which productivity is high.

At the aggregate level, we assume the existence of a matching technology that

${ }^{7}$ The model developed in this section is drawn from Farmer (2012a). 
determines aggregate employment $\bar{L}_{t}$ as a function of aggregate resources devoted to recruiting, $\bar{V}_{t}$, and the aggregate number of unemployed searching workers, $\bar{U}_{t}$. This function is given by,

$$
\bar{L}_{t}=m\left(\bar{V}_{t}, \bar{U}_{t}\right) \equiv\left(\Gamma \bar{V}_{t}\right)^{1 / 2},
$$

where $\bar{U}_{t}$ does not appear in the aggregate matching function because the assumption that workers are fired every period implies that the number of searching workers is equal to 1 at the beginning of every period. ${ }^{8}$ Because the economy is endowed with one unit of labor, this assumption implies that

$$
L_{t}+U_{t}=1 \text {. }
$$

The parameter $\Gamma$ in the matching function determines the efficiency of the matching technology. In a symmetric equilibrium where $L_{t}=\bar{L}_{t}$, we may combine Equations (1), (2) and (3) to find an expression for $Y_{t}$ in terms of $L_{t}$ and $\bar{L}_{t}$

$$
Y_{t}=K_{t}^{\alpha}\left[L_{t}\left(1-\frac{\bar{L}_{t}}{\Gamma}\right)\right]^{1-\alpha}
$$

where $\bar{L}_{t} / \Gamma=1 / q_{t}$.

Equation (4) is the private production function. This function represents the connection between the output of an individual firm, $Y_{t}$, the labor and capital inputs at the level of the firm, $L_{t}$ and $K_{t}$, and the labor input of all other firms, $\bar{L}_{t}$. The private production function is distinct from the social production function, Equation (5),

$$
\bar{Y}_{t}=\bar{K}_{t}^{\alpha}\left[\bar{L}_{t}\left(1-\frac{\bar{L}_{t}}{\Gamma}\right)\right]^{1-\alpha},
$$

which represents the connection between aggregate output $\bar{Y}_{t}$ and aggregate labor and capital inputs, $\bar{L}_{t}$ and $\bar{K}_{t}$. We illustrate the properties of the social production function in Figure 1. On this figure, we see that output is increasing in employment up to a maximum that occurs at $\Gamma / 2$.

The social production function exhibits search externalities. For large values of aggregate employment, $\bar{L}_{t}$, the labor market becomes tighter and further reduction of unemployment is costly. As firms allocate more workers to the recruiting activity, those workers are withdrawn from production. If employment increases beyond $\Gamma / 2$, additional increases in aggregate employment become counter pro-

\footnotetext{
${ }^{8}$ This simplification requires the assumption that workers can, in effect, recruit themselves. Farmer (2012a) discusses the assumption further and Farmer (2013) drops the assumption and treats employment as an additional state variable. Nothing of substance is added to the model by complicating it in this way and we have chosen, in this paper, to use the simpler model, where labor is not a state variable, for expositional purposes.
} 


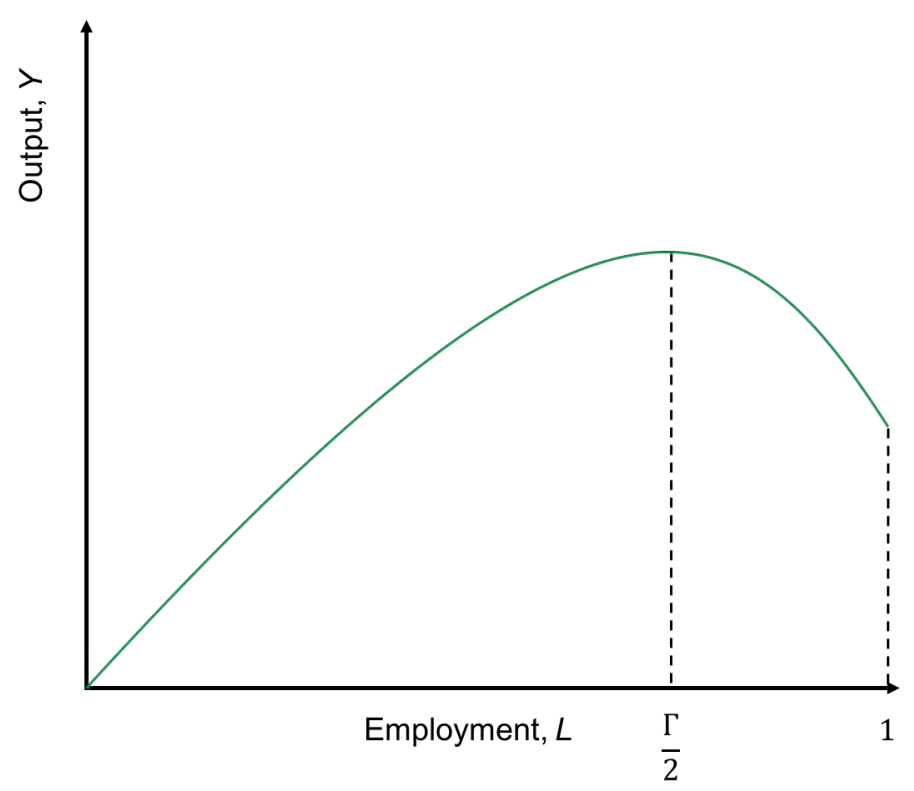

Figure 1. The Social Production Function

ductive. $^{9}$ The value of unemployment at the social optimum,

$$
U=1-\frac{\Gamma}{2},
$$

is our definition of the natural rate of unemployment. ${ }^{10}$

\section{Aggregate Demand}

There is a continuum of households. Each household lives for two periods and derives utility from consumption when young $C_{t}^{y}$, consumption when old $C_{t+1}^{o}$, and real money balances purchased in the first period of their life $M_{t+1} / P_{t}$. Labor does not deliver disutility, and therefore the participation rate is always equal to $1 .^{11}$

Preferences are given by a logarithmic utility function and we assume that

\footnotetext{
${ }^{9}$ In the special case when $\Gamma=1$, output is maximized when $\bar{L}=1 / 2$ and, when $\bar{L}=1$, aggregate output falls to zero.

${ }^{10}$ Friedman (1968) defined the natural rate of unemployment to be the equilibrium rate. That definition only makes sense when equilibrium is unique. In our model, there is a continuum of steady state equilibria and in this framework it makes more sense to define the natural rate of unemployment to be the social planning optimum.

${ }^{11}$ Allowing for disutility from participation in the labor market would make the participation rate endogenous. However, the connection between the participation rate and the unemployment rate appears limited. The participation rate is driven mostly by demography and does not exhibit pronounced comovement with the business cycle.
} 
households maximize expected utility,

$$
u_{t}=\log \left(C_{t}^{y}\right)+\beta \mathbb{E}_{t}\left[\log \left(C_{t+1}^{o}\right)\right]+\delta \log \left(\frac{M_{t+1}}{P_{t}}\right) .
$$

In the first period of their life, households earn labor income $W_{t} L_{t}$. They use their income to purchase current consumption $P_{t} C_{t}^{y}$, capital goods $P_{K, t} K_{t+1}$ and government bonds $B_{t+1}$. All prices are in terms of money.

In the second period of life, households rent capital to firms and earn the rental payment $R_{t+1} K_{t+1}$, and interest accrued on their loan to the government $\left(1+i_{t}\right) B_{t+1}$. In addition, at the end of the period they sell capital and money to the new young generation. Their first and second period budget constraints are given by the following equations:

$$
\begin{gathered}
P_{t} C_{t}^{y}+M_{t+1}+B_{t+1}+P_{K, t} K_{t+1}=W_{t} L_{t}, \\
P_{t+1} C_{t+1}^{o}=\left(R_{t+1}+P_{K, t+1}\right) K_{t+1}+\left(1+i_{t}\right) B_{t+1}+M_{t+1} .
\end{gathered}
$$

The no-arbitrage condition implies that the return to government bonds must be equal to the return on physical capital, when evaluated in terms of utility from consumption in the second period,

$$
\mathbb{E}_{t}\left[\frac{\beta}{C_{t+1}^{o}}\left(\frac{1+i_{t}}{P_{t+1} / P_{t}}-\frac{\left(P_{K, t+1}+R_{t+1}\right) / P_{t+1}}{P_{K, t} / P_{t}}\right)\right]=0
$$

Here the first term in round parentheses is the expected real interest rate payed on government bonds. The second term in the round parentheses is the real return to physical capital. In words, this equation states that the young are indifferent between investing in bonds and capital. Using this condition, and defining real savings of the young in non-monetary assets as follows,

$$
S_{t}^{y}=\left(B_{t+1}+P_{K, t} K_{t+1}\right) / P_{t},
$$

we can write the young's consumption function $C_{t}^{y}$, the demand for real money balances $M_{t+1} / P_{t}$ and the young's real savings function $S_{t}^{y}$ that solve the utility maximization problem:

$$
\begin{gathered}
C_{t}^{y}=\frac{1}{1+\beta+\delta} \frac{W_{t} L_{t}}{P_{t}} \\
\frac{M_{t+1}}{P_{t}}=\frac{\delta}{1+\beta+\delta}\left(\frac{1+i_{t}}{i_{t}}\right) \frac{W_{t} L_{t}}{P_{t}} .
\end{gathered}
$$




$$
S_{t}^{y}=\frac{W_{t} L_{t}}{P_{t}}-C_{t}^{y}-\frac{M_{t+1}}{P_{t}} .
$$

Substituting for consumption and money balances in (14) gives the following alternative expression for saving

$$
S_{t}^{y}=\frac{1}{1+\beta+\delta}\left(\beta-\frac{\delta}{i_{t}}\right) \frac{W_{t} L_{t}}{P_{t}} .
$$

In our model, the saving of the young is an increasing function of the money interest rate because money and consumption are substitutes in utility and the money interest rate is the opportunity cost of holding money. In the traditional IS-LM model, saving is sometimes written as an increasing function of the real interest rate. That channel for the interest rate to influence saving is missing from our model because of our simplifying assumptions that utility is logarithmic and that labor supply occurs only in youth. ${ }^{12}$

To simplify the exposition of our model, we assume that government bonds are in zero net supply and we concentrate on the role of monetary policy. We study a policy in which the central bank keeps the money supply $M_{t}$ constant, and where that policy is expected to continue forever. In that environment we study the effect of an unanticipated change in $M_{t}$ that we implement through an unanticipated cash transfer to the old generation. In future work we plan to study the role of fiscal interventions.

\section{The Role of Beliefs}

Although our work is superficially similar to the IS-LM model and its modern New Keynesian variants; there are significant differences. By grounding the aggregate supply function in the theory of search and, more importantly, by dropping the Nash bargaining assumption, we arrive at a theory where preferences, technology and endowments are not sufficient to uniquely select an equilibrium.

Following Farmer (2012a) we close our model by making beliefs fundamental. Farmer studies that assumption in the context of a purely real representative agent model. In the current paper we explore the implications of multiple steady state equilibria in a model where money is used as a means of exchange and where the representative agent assumption is replaced by a model of overlapping generations. ${ }^{13}$

\footnotetext{
${ }^{12}$ Relaxing the unitary elasticity of intertemporal substitution by considering a utility function of the form $U\left(C^{y}, C^{o}, M / P\right)=\log \left(C^{y}\right)+\beta \log \left(C^{o}+\bar{C}\right)+\delta \log (M / P)$ would add the real interest rate as an argument of the savings function. When $\bar{C}>0$, the intertemporal substitution effect dominates the income effect, making the savings function increasing in both money interest rate as the price of money and the real interest rate as the relative price of consumption when old. In this model, we adopt $\bar{C}=0$ for expository purposes.

${ }^{13}$ Plotnikov $(2013,2014)$ explores a similar idea in a version of a real business cycle model, closed with Farmer's (2012a) Keynesian search model of the labor market. Plotnikov closes his model with the assumption that beliefs about future human wealth are adaptive and he shows that a model, closed in this way, generates jobless recoveries.
} 
The assumption that beliefs are fundamental is not sufficient to explain how they are fundamental and the belief function could take different forms. In our view, beliefs are most likely learned and we see the work of George Evans and Seppo Honkapohja (Evans and Honkapohja, 2001) as a promising avenue in describing how a particular belief function may arise. In this respect beliefs are similar to preferences. ${ }^{14}$

Economists assume that a human being is described by a preference ordering and that by the time a person achieves adulthood he or she is able to make choices over any given commodity bundle. But those choices are learned during childhood; they are not inherited. At the age of twenty one, an Italian is likely to choose a glass of wine with a meal; a German is more likely to choose a beer. But a German child, adopted into an Italian family at birth, will grow up with the preferences of his adoptive parents, not with those of his biological parents. Beliefs, in our view, are similar.

During a period of stable economic activity, people learn to make forecasts about future variables by projecting observations of variables of interest on their information from the recent past. When there is a change in the environment, caused by a policy shift or a large shock to fundamentals, they continue to use the beliefs that they learned from the past. That argument suggests that we should treat the parameters of the belief function in the same way that we treat the parameters of the utility function. They are objects that we would expect to remain stable over the medium term and that should be estimated using econometric methods.

In this paper we investigate one plausible assumption about the belief function and we study its role as a way of closing our model. We assume that beliefs are determined by the equation

$$
\mathbb{E}_{t}^{*}\left[\frac{P_{K, t+1}}{P_{t+1}}\right]=\Theta_{t}
$$

where the expectations operator in Equation (16) is subjective and reflects the beliefs of a representative person of the probabilities of future events. To impose discipline on our analysis we assume that expectations are rational; that is,

$$
\mathbb{E}_{t}^{*}\left[\frac{P_{K, t+1}}{P_{t+1}}\right]=\mathbb{E}_{t}\left[\frac{P_{K, t+1}}{P_{t+1}}\right]=\Theta_{t},
$$

where the expectation $\mathbb{E}$ is taken with respect to the true probabilities in a rational expectations equilibrium.

Because there is no aggregate investment in our model, capital represents an input in fixed supply. We interpret $P_{K}$ to be the the average price of assets traded in the stock market and changes in $P_{K}$ represent self-fulfilling shifts in perceptions

\footnotetext{
${ }^{14}$ The discussion in this section closely follows the presentation in Farmer (2016a).
} 
of financial wealth.

\section{The Equations of the Model}

The equilibrium of our model is described by the following seven equations. To obtain these equations, we used two facts. First, factor incomes are proportional to GDP,

$$
\frac{R_{t} K_{t}}{P_{t}}=\alpha Y_{t} \quad \text { and } \quad \frac{W_{t} L_{t}}{P_{t}}=(1-\alpha) Y_{t}
$$

and second, in a symmetric equilibrium, social employment equals individual employment and each firm employs one unit of capital,

$$
L_{t}=\bar{L}_{t} \quad \text { and } \quad K_{t}=1
$$

Now we turn to a description of each of the seven equations that comprise our model.

$$
\frac{1-\alpha}{1+\beta+\delta}\left(\beta-\frac{\delta}{i_{t}}\right) Y_{t}=\frac{P_{K, t}}{P_{t}}
$$

Equation (20) equates the demand for interest bearing assets by the young (the young's real savings function $S_{t}^{y}$ ) to the real value of the single unit of capital $\left(P_{K, t} / P_{t}\right)$ available in the economy. This is our analog of the IS curve.

$$
\frac{M_{t+1}^{*}}{P_{t}}=\frac{(1-\alpha) \delta}{1+\beta+\delta}\left(\frac{1+i_{t}}{i_{t}}\right) Y_{t}
$$

Equation (21) is the money market clearing condition and it is our equivalent of the LM curve. Here $M_{t+1}^{*}$ is the stock of money exogenously determined by the central bank and available for the young generation to hold as part of their optimal portfolio.

$$
\mathbb{E}_{t}\left[\frac{\beta}{C_{t+1}^{o}}\left(\frac{1+i_{t}}{P_{t+1} / P_{t}}-\frac{\left(P_{K, t+1}+\alpha P_{t+1} Y_{t+1}\right) / P_{t+1}}{P_{K, t} / P_{t}}\right)\right]=0 .
$$

Equation (22) is the no-arbitrage relation between the money interest rate and the return to capital. This equation represents the assumption that physical capital and government bonds pay the same rate of return and it has no analog in the simplest version of the IS-LM model.

$$
P_{t} C_{t}^{o}=\alpha P_{t} Y_{t}+P_{K, t}+M_{t+1}^{*} .
$$

Equation (23) is the expenditure function of the old. It says that the old's expenditure on consumption must be equal to the income plus principal from selling 
capital plus the value of the money held by the old.

$$
Y_{t}=\left[\left(1-\frac{L_{t}}{\Gamma}\right) L_{t}\right]^{1-\alpha}
$$

Equation (24) is the social production function. This equation serves only to determine employment and it plays the role of the 45 degree line in the Keynesian Cross model.

Next, we define GDP to be the sum of the consumption of the two generations

$$
Y_{t}=C_{t}^{y}+C_{t}^{o},
$$

and, finally, we add a seventh equation, the belief function (26).

$$
\mathbb{E}_{t}\left[\frac{P_{K, t+1}}{P_{t+1}}\right]=\Theta_{t}
$$

The belief function distinguishes our model from the New Keynesian approach and it replaces the New Keynesian Phillips curve. In the absence of this new element, the other six equations would not uniquely determine the seven endogenous variables $\left\{Y_{t}, P_{t}, i_{t}, P_{K, t}, L_{t}, C_{t}^{y}, C_{t}^{o}\right\}$. The belief function is an equation that determines how much households are willing to pay for claims on the economy's capital stock. It represents the aggregate state of confidence or 'animal spirits' and, in combination with the other six equations of the model, the belief function selects an equilibrium.

In our comparative statics exercises in Section VII, we compare two alternative specifications for the belief function. In one specification we assume that,

$$
\Theta_{t}=\Theta \text { for all } t
$$

We call this assumption fixed beliefs and it amounts to the assumption that, in the collective view of asset market participants, the stock market has some fixed real value measured in terms of the CPI.

In a second specification we assume that

$$
\Theta_{t}=\frac{P_{K, t}}{P_{t}}
$$

We call this assumption adaptive beliefs and it amounts to the assumption that, in the collective view of market participants, the real value of the stock market is a random walk. This second assumption, which is a better description of the actual behavior of stock market prices, has a non-standard implication that we draw attention to in Section IX.C. It implies that unanticipated shocks to the money 
supply can have permanent effects on the steady state unemployment rate. ${ }^{15}$

Equations (20), (21), (22), (23), (25), and (26) determine aggregate demand. Given beliefs $\left\{\Theta_{t}\right\}$ and monetary policy $M_{t}^{*}$, these equations select an equilibrium sequence for $\left\{Y_{t}, P_{t}, i_{t}, P_{K, t}, C_{t}^{y}, C_{t}^{o}\right\}$ and Equation (24) determines how much labor firms need to hire to satisfy aggregate demand. Since employment is determined recursively, in the subsequent parts of the paper we dispense with Equation (24) in our discussion of equilibrium.

\section{The IS-LM-NAC Representation of the Steady-State}

In this section, we show that the steady-state equilibrium of our model admits a representation that is similar to the IS-LM representation of the General Theory developed by Hicks and Hansen. The IS-LM model is a static construct in which the price level is predetermined. To provide a fully dynamic model, Samuelson closed the IS-LM model by adding a price adjustment equation that later NewKeynesian economists replaced with the New-Keynesian Phillips curve.

We take a different approach. We select an equilibrium by closing the labor market with a belief function. In our model, the IS curve, the LM curve and the NAC curve, intersect to determine the price level, GDP and the interest rate in a steady state equilibrium. Unlike the neoclassical synthesis, in our model high Pareto inefficient unemployment can persist forever in the presence of pessimistic beliefs. And unlike the interpretation of animal spirits that was popularized by George Akerlof and Robert Shiller (2009), pessimistic animal spirits are fully rational. The people in our model are rational and have rational expectations but they are, sometimes, unable to coordinate on a socially efficient outcome.

The following equations characterize the steady-state equilibrium:

$$
\begin{aligned}
\text { IS: } & \frac{1-\alpha}{1+\beta+\delta}\left(\beta-\frac{\delta}{i}\right) Y=\Theta, \\
\text { LM: } & \frac{M}{P}=\frac{(1-\alpha) \delta}{1+\beta+\delta}\left(\frac{1+i}{i}\right) Y, \\
\text { NAC: } & i=\frac{\alpha Y}{\Theta} .
\end{aligned}
$$

Equations (29) - (31) determine the three unknowns: $Y, i$ and $P$, for given values of $M$ and $\Theta$. We treat $\Theta=\mathbb{E}\left[P_{K} / P\right]$ as a new exogenous variable that reflects investor confidence about the real value of their financial assets and by making $\Theta$ exogenous we provide a new interpretation of Keynes' idea that equilibrium is selected by 'animal spirits'.

In $(Y, i)$ space, the IS and NAC curves determine $Y$ and $i$ and the price level adjusts to ensure that the LM curve intersects the IS and NAC curves at the

\footnotetext{
${ }^{15}$ Farmer $(2012 \mathrm{~b}, 2015)$ finds evidence that the real value of the stock market and the unemployment rate can be parsimoniously modeled as co-integrated random walks. Our work in this paper provides one possible theoretical model that can explain this finding.
} 
steady state. We illustrate the determination of a steady state equilibrium in Figure 2 .

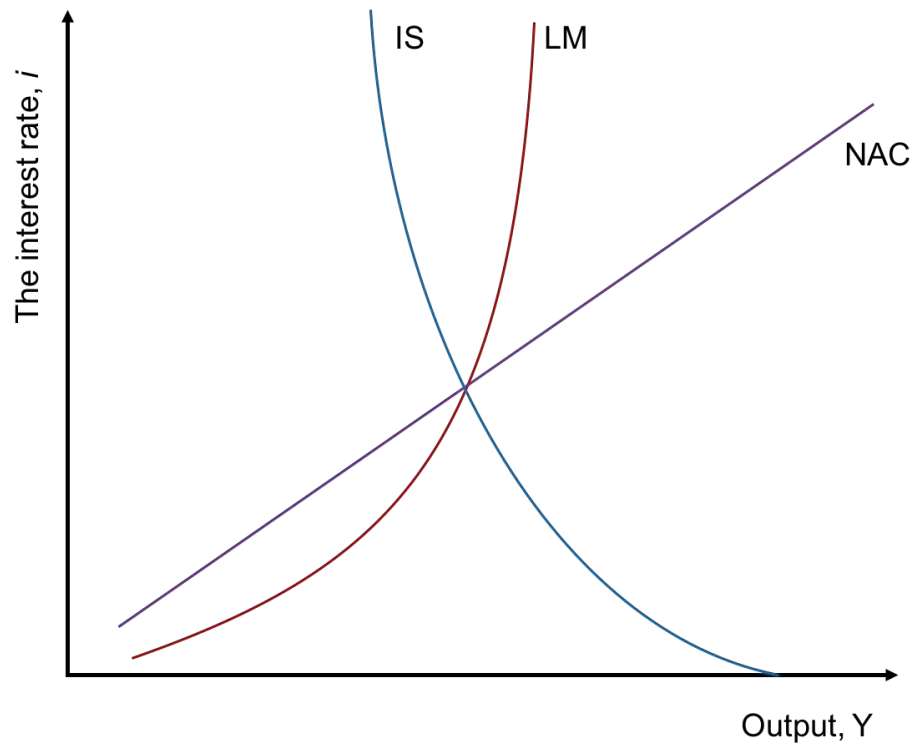

Figure 2. The IS-LM-NAC Representation of the Steady State

The IS curve, Equation (29), is downward sloping and its position is determined by animal spirits, $\Theta$ where,

$$
\Theta=\mathbb{E}_{t}\left[\frac{P_{K, t+1}}{P_{t+1}}\right]
$$

In a steady state equilibrium, beliefs about future wealth are self-fulfilling. When people feel wealthy, they are wealthy. Increased confidence shifts both the IS curve, and the NAC curve, to the right. The economy arrives eventually at a new steady state equilibrium with higher output, but the path by which the economy attains this steady state depends on how people form expectations about future prices. We analyze the movement between equilibria in Section VII.

\section{Two Comparative Static Exercises}

In this section we ask how shifts in exogenous driving variables affect the equilibrium values of $Y, i$ and $P$. We conduct two comparative static exercises. In the first exercise we increase $\Theta$ from a low value to a higher value at some date, $t=1$, and we assume that it remains constant thereafter. In the second exercise, 
we hold $\Theta$ fixed forever and we increase the stock of money. ${ }^{16}$

Consider first, the experiment of an increase in the belief about the value of financial wealth. A greater value of $\Theta$ influences output through two channels. Firstly, since consumers believe, correctly, that they are wealthier, real consumption of goods and services increases. The IS curve shifts to the right. Moreover, higher asset prices reduce the interest rate and the NAC curve becomes flatter. These effects are illustrated in Figure 3.

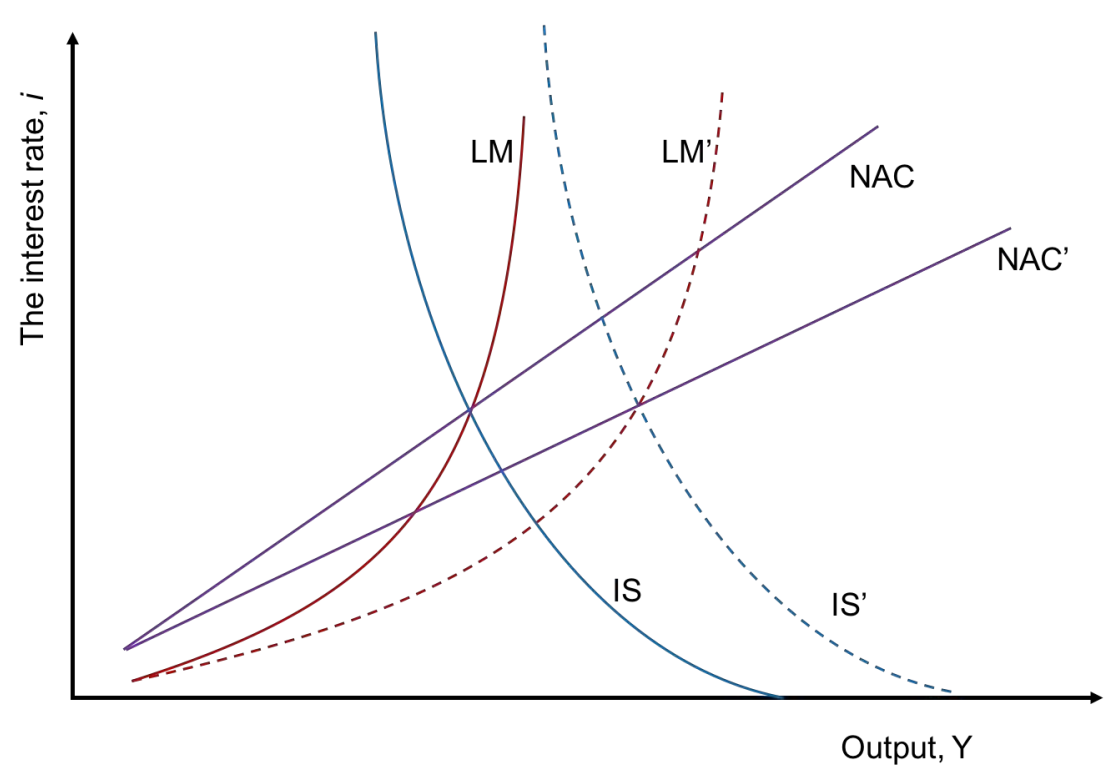

Figure 3. An InCREase in CONFidence

As people become more confident, the IS curves shifts to the right beginning at the solid IS curve and ending at the dashed IS curve. At the same time, the NAC curve shifts down and to the right, from the solid NAC to the dashed NAC curve. Because output increases, the demand for real money balances increases, and the price level must be lower in the new steady state equilibrium. This is reflected on Figure 3 by a rightward shift in the LM curve. Because the class of Cobb-Douglas utility functions implies a unitary elasticity of intertemporal substitution, the intertemporal substitution effect and the income effect cancel each other out and, at the new equilibrium, the interest rate remains unchanged.

Consider next, the effect of an increase in the stock of money, which we illustrate on Figure 4.

Equations (29) and (31) determine the equilibrium values of output and the

\footnotetext{
${ }^{16}$ In section IX we consider an alternative model of expectation formation in which the belief about the future value of capital is equal to its current realized value.
} 
interest rate independently of the stock of money. The demand for real balances depends only on $Y$ and $i$ and, once these variables have been determined, the price level, $P$, adjusts to equate the real value of the money supply to the real value of money demand. It follows that changes in the supply of money will cause proportional changes in the price level and the nominal value of wealth, leaving output and the interest rate unchanged.

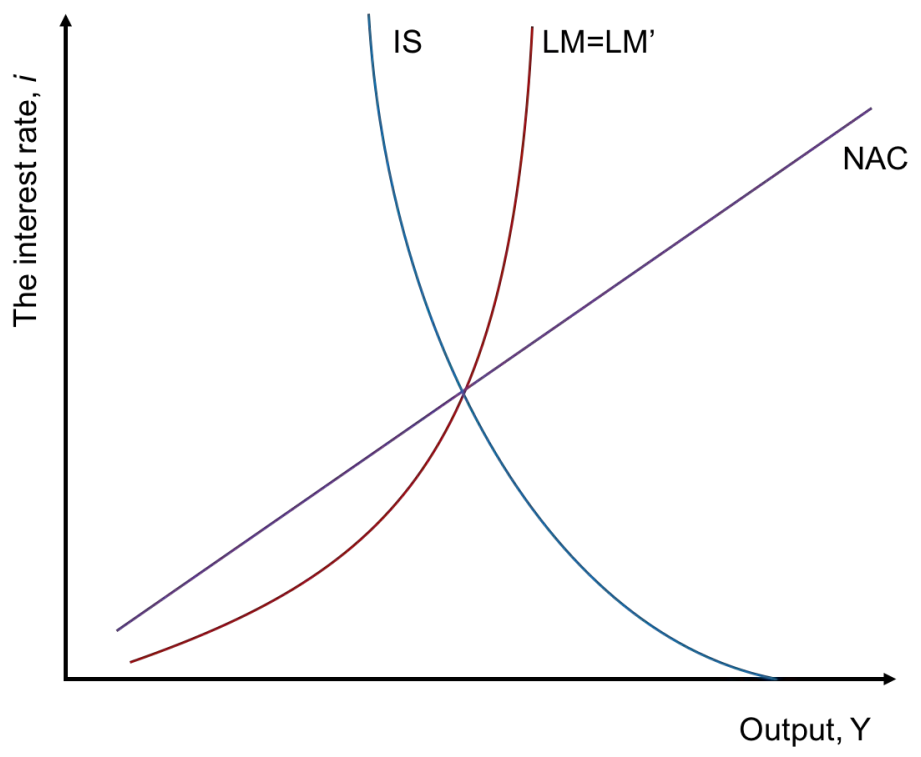

Figure 4. An Increase in the Money Supply

Figure 4 illustrates the effects of a change in $M$ on a graph. The LM curve after the increase in the money supply is identical with the LM curve before the change, illustrating the concept that money, in our model, is neutral. However, as we will show in Section IX, this result depends on the form of the belief function. If beliefs about the future value of financial wealth depend on the current realized value of wealth, an increase in the money supply may have a permanent real effect on output through its effect on business and consumer confidence.

\section{Dynamic Equilibria}

In this section we shift from a comparison of steady states to a description of complete dynamic equilibria. To study the equilibria of the complete model, we use the algorithm, GENSYS, developed by Christopher Sims (2001). First, we choose a constant sequence $\{M, \Theta\}$ to describe policy and we log-linearize the dynamic equations around a steady state. Let

$$
x_{t} \equiv\left[y_{t}, \tilde{i}_{t}, p_{t}, p_{K, t}, \mathbb{E}_{t}\left[y_{t+1}\right], \mathbb{E}_{t}\left[p_{t+1}\right], \mathbb{E}_{t}\left[p_{K, t+1}\right]\right]^{\prime}
$$


be log deviations of the endogenous variables from their steady state values. Let

$$
\varepsilon_{t} \equiv\left[m_{t}, \theta_{t}\right]^{\prime}
$$

log deviations of the exogenous variables from their initial values and define three new variables,

$$
\begin{aligned}
\eta_{t}^{1} & \equiv p_{t}-\mathbb{E}_{t-1}\left[p_{t}\right], \\
\eta_{t}^{2} & \equiv p_{K, t}-\mathbb{E}_{t-1}\left[p_{K, t}\right], \\
\eta_{t}^{3} & \equiv y_{t}-\mathbb{E}_{t-1}\left[y_{t}\right] .
\end{aligned}
$$

These new variables represent endogenous forecast errors. Next, we log-linearize equations (20) - (22) and Equation (26) and we append them to equations (35) (37). That leads to the following linear system of seven equations in seven unknowns,

$$
\Gamma_{0} x_{t}=\Gamma_{1} x_{t-1}+\Psi \varepsilon_{t}+\Pi \eta_{t},
$$

The matrix $\Psi$ is derived from the linearized equations and it explains how shocks to $M$ and shocks to $\Theta$ influence each of the equations of the model. Once we have provided a model of beliefs, the steady state of our system is determinate. For every specification of the belief function, Equation (26), there is a unique steady state. In this sense, our animal spirits model is similar to any dynamic stochastic general equilibrium model. For a given specification of fundamentals, there is a unique predicted outcome.

But the fact that the model, augmented by a belief function, has a unique steady state, is not enough to uniquely determine a dynamic equilibrium. To establish uniqueness of a dynamic equilibrium, we must show that for every representation of fundamentals, where fundamentals now include beliefs, there is a unique dynamic path converging to the steady state. The uniqueness or non-uniqueness of dynamic equilibria is determined by the properties of the matrices $\Gamma_{0}$ and $\Gamma_{1}$, in Equation (38).

To establish the properties of a dynamic equilibrium, we must provide a calibrated version of the model since determinacy of equilibrium is, in general, a numerical question. To study determinacy, we used the calibration from Table 1.

TABle 1 - CALibration

\begin{tabular}{clr}
\hline Parameter & \multicolumn{1}{c}{ Definition } & Value \\
\hline$\alpha$ & Share of capital in output & .33 \\
$\beta$ & Subjective discount rate & .50 \\
$\delta$ & Coefficient on real money balances in utility & .05 \\
\hline
\end{tabular}


For this calibration, we found that our model has one degree of indeterminacy. In words, that implies that for any set of initial conditions there is a one dimensional continuum of dynamic paths, all of which converge to a given steady state. In practice, it means that the rational expectations assumption is not sufficient to uniquely determine all three of the forecast errors, $\eta_{t}$, as functions of the fundamental shocks, $\varepsilon_{t}$. When the model displays dynamic indeterminacy, there are many ways that people may use to forecast the future, all of which are consistent with a rational expectations equilibrium (Farmer, 1991, 1993).

Following Farmer (2000), we resolve this indeterminacy by selecting a particular equilibrium for which

$$
\eta_{t}^{1} \equiv p_{t}-\mathbb{E}_{t-1}\left[p_{t}\right]=0
$$

This equation is a special case of Equation (35). In words, this assumption means that money prices are set one period in advance. It is important to note that price stickiness does not violate the property of rational expectations. The equilibrium with sticky prices is one of many possible equilibria of the economy where agents form self-fulfilling beliefs about wealth and it is an equilibrium that explains an important property of the data: Unanticipated monetary shocks have real short run effects and they feed only slowly into prices.

\section{Three Dynamic Experiments}

In this section, using the parameter values from Table 1, we analyze three dynamic experiments. In the first experiment, we begin from a steady state, and we ask how a permanent unanticipated increase in confidence affects the endogenous variables of the model. In the second and third experiments, we ask how a permanent unanticipated increase in the stock of money affects the economy.

In our second experiment, the belief of households about the future real value of the stock market is invariant to its current value. In our third experiment, households expect the future real value of the stock market to be equal to its current value. We refer to the alternative assumptions in experiments two and three as fixed and adaptive beliefs.

In the case of fixed beliefs, the experiment of increasing the money supply, has the same effects that it would have in a classical model in which output is supply determined: Money is neutral. In contrast, if households form their beliefs adaptively, a permanent increase in the money supply has a permanent effect on output. Money is non-neutral because it increases the real value of the stock market and that increase is translated, through a confidence effect, into a permanent increase in beliefs about the value of the stock market.

Is it reasonable to think that a change in a nominal variable may have permanent real effects? We think so. Farmer (2012c) and Farmer and Nicolò (2016) have estimated a model of the US economy in which beliefs about future income growth 
are equal to current income growth and they have shown that a belief function of this kind outperforms standard New-Keynesian models closed by a Phillips curve. In their model, the central bank sets the money interest rate and changes in the interest rate have a permanent effect on the unemployment rate by shifting the economy from one equilibrium to another. In our model a similar shift from one steady state equilibrium to another is achieved by an increase in the money supply which raises share prices and has a permanent effect on animal spirits.

\section{A. Experiment 1: A Shock to Confidence}

Figure 5 displays the dynamic paths of eight variables in response to a one time increase in beliefs about the future value of capital. We call this a shock to confidence.
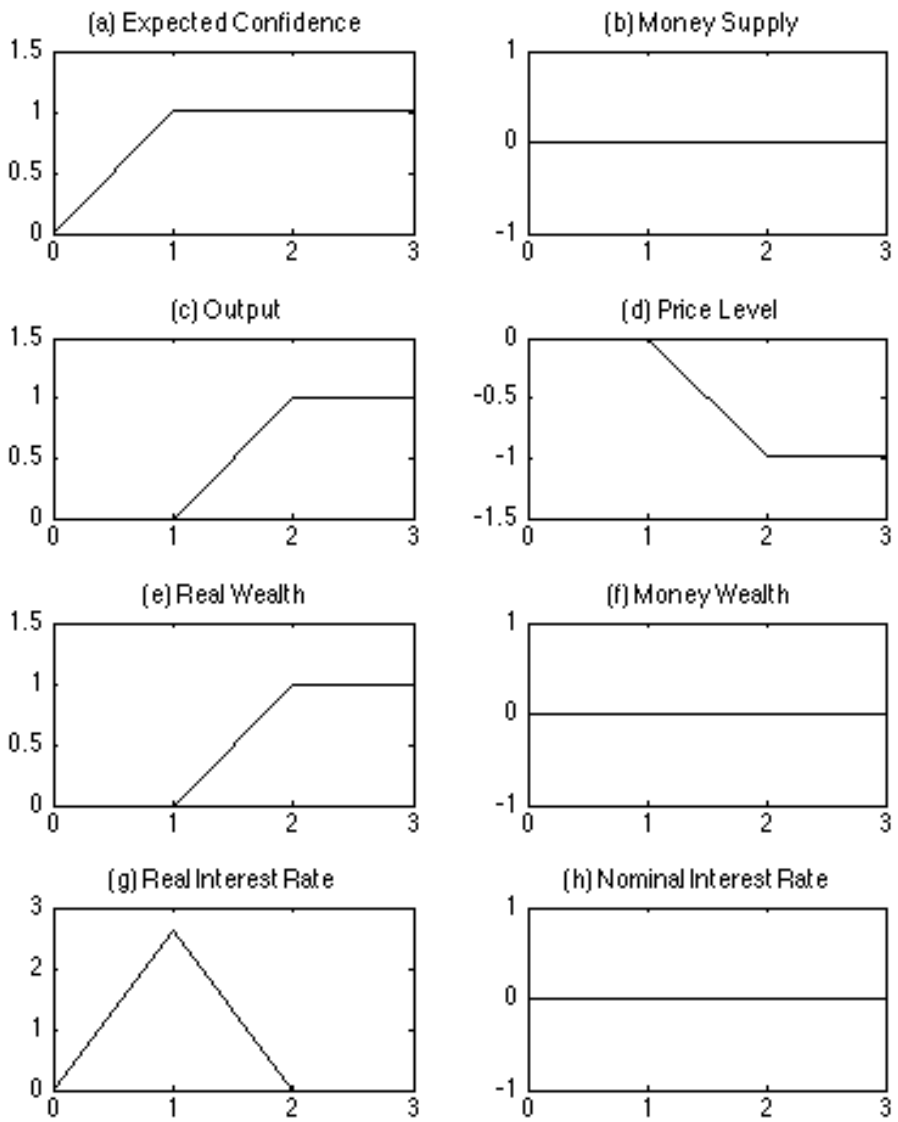

Figure 5. A Permanent Shock to Confidence

Panel (a) depicts the value of beliefs about the future real value of the stock 
market, $\mathbb{E}_{t}\left[P_{K, t+1} / P_{t+1}\right]$. This is the variable we refer to as $\Theta$. In our first experiment, $\Theta$ increases by one percent and it remains one percent higher for ever after. Panel (b) shows the value of the money supply, which we hold fixed for this experiment.

Panel (c) shows that, in period 2, output increases and remains permanently higher by one percent. This occurs because rational forward-looking consumers increase their spending on goods and services and firms respond by hiring additional workers to produce these goods. Panel (d) shows that the price level falls and stays permanently lower. Greater output increases the demand for real money balances and the price level must fall to equate the demand and supply of money.

Panel (e) shows that, in period 2, the realized value of real stock-market wealth increases by one percent. That follows from the rational expectations assumption; people expected the value of share prices to increase and, in a rational expectations equilibrium, that belief is supported by the way that people form their beliefs in period 2 and in all subsequent periods. From panel (g), we see that the real interest rate jumps up in period 1 and reverts to its steady-state value thereafter. Because the price level and the money interest rate do not adjust in the first period, the real interest rate adjustment is achieved by a self-fulfilling adjustment to the expected future price level.

We want to draw attention to several features of these impulse responses. First, although adjustment to a confidence shock is delayed, the delay lasts for only one period. That follows from the stylized nature of a model in which there are no endogenous propagation mechanisms. Second, prices do not respond at all in the first period. Unlike the New-Keynesian model, prices are not sticky because of adjustment costs or restrictions on choice. They are fixed because people rationally anticipate that output, not prices, will respond to unanticipated shocks.

If models in this class are to be taken seriously as descriptions of data, they must be tied down by an assumption about how beliefs are formed. To give the model empirical content, one must assume that the belief function remains time invariant at least over the medium term. If that assumption holds, the parameters of the belief function can be estimated in the same way that econometricians estimate preference parameters. ${ }^{17}$ We propose to tie down our model by assuming that the covariance of prices with contemporaneous variables should be treated as a separate parameter of the belief function and that this parameter should be estimated using standard econometric methods.

\section{B. Experiment 2: A Shock to the Money Supply with Fixed Beliefs}

In subsections IX.B and IX.C we show that the way economic agents form beliefs about the future, matter for the long-term effect of monetary shocks.

\footnotetext{
${ }^{17}$ See Farmer (2012c) and Farmer and Nicolò (2016) for examples of empirical exercises that estimate a version of this model on U.S. data.
} 

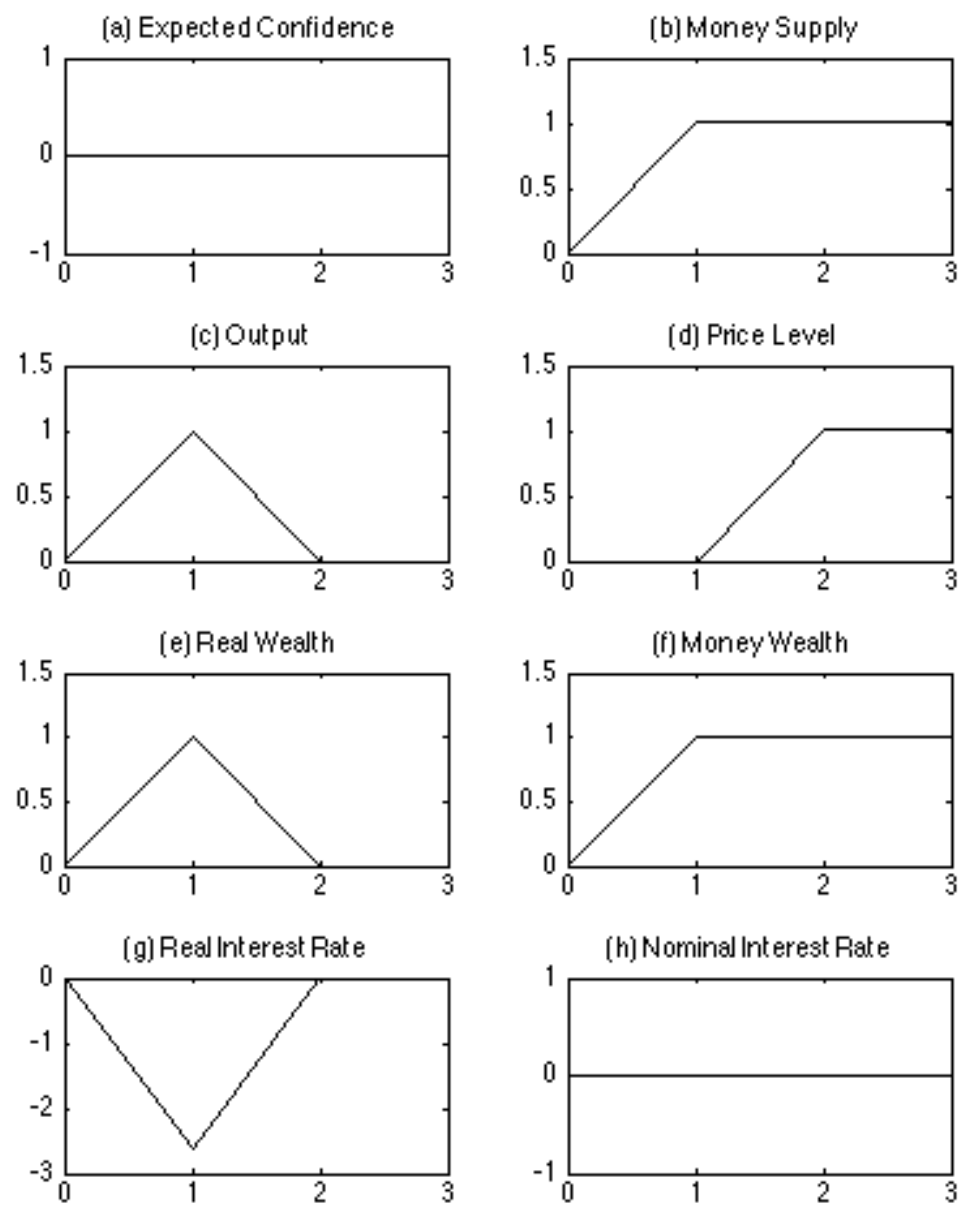

Figure 6. A Permanent Shock to the Supply of Money under Fixed Beliefs

In subsection IX.B, we consider the case of fixed beliefs, which we model with Equation (40),

$$
\mathbb{E}_{t}\left[\frac{P_{K, t+1}}{P_{t+1}}\right]=\Theta
$$

Figure 6 displays the dynamic paths for the variables of this economy in response to a shock to the money supply when beliefs are modeled in this way. This shock is reflected in Panel (b) which depicts the time path for $M$. We assume that at date $1, M$ increases by one percent and that it remains one percent higher forever after. Panel (a) reflects our assumption that beliefs are fixed.

Panel (c) shows that output increases temporarily in the first period by one percent. This happens because prices are predetermined and are unable to adjust 
until period 2. Instead, the increase in the money supply causes an increase in aggregate demand that is met by a corresponding temporary increase in output and employment. Firms hire more workers to satisfy the increased aggregate demand.

Panel (d) shows that prices respond in period 2 and remain 1 percent higher. This increase neutralizes the increase in the money supply and is consistent with the return to steady state of output reflected in panel (c). Panels (e) and (f) show that the real value of shares in the stock market increases and then returns to its original value. In contrast, the money value of shares in the stock market goes up by one percent and remains permanently higher. From panel (g) we see that the real interest rate falls in period 1 and panel $(\mathrm{h})$ shows that the money interest rate remains constant during the entire exercise.

\section{Experiment 3: A Shock to the Money Supply with Adaptive Beliefs}

To model adaptive beliefs, we replace Equation (40), with Equation (41),

$$
\mathbb{E}_{t}\left[\frac{P_{K, t+1}}{P_{t+1}}\right]=\frac{P_{K, t}}{P_{t}} .
$$

When beliefs are adaptive, households expect the real value of the stock market to be a random walk. This is a special case of a more general model in which beliefs are formed by the following adaptive expectations equation, ${ }^{18}$

$$
\mathbb{E}_{t}\left[\frac{P_{K, t+1}}{P_{t+1}}\right]=\lambda\left(\frac{P_{K, t}}{P_{t}}\right)+(1-\lambda) \mathbb{E}_{t-1}\left[\frac{P_{K, t}}{P_{t}}\right], \quad \lambda \in[0,1]
$$

Figure 7 displays the dynamic paths for the variables of this economy in response to a shock to the money supply when beliefs about the real value of shares in the stock market are determined by a random walk. We assume that $M$ increases by one percent and that it remains one percent higher for ever after. The shock to the money supply is reflected in Panel (a).

The increase in the stock of money causes an increase in the money price of financial assets; this is shown in Panel (f). Because the price of goods is predetermined, the increase in the nominal share price is also an increase in its real price as shown in Panel (e). Panel (b) shows that beliefs about the future real value of shares respond to this monetary shock and they remain permanently one percent higher in all subsequent periods. Panel (c) shows that the increase in the real value of the stock market triggers an increase in output that is sustained because of the effect of the increase in the money supply on beliefs, as reflected in Panel (b). Panels (d), (g) and (h) show that the price level, and the real and nominal interest rates do not respond at all to a one off permanent increase in the money

\footnotetext{
${ }^{18}$ We have restricted ourselves to the special case of $\lambda=1$ because Farmer (2012c) estimated a model that allows $\lambda$ to lie in the interval $[0,1]$ and found that empirically, the data favors a model where $\lambda=1$.
} 

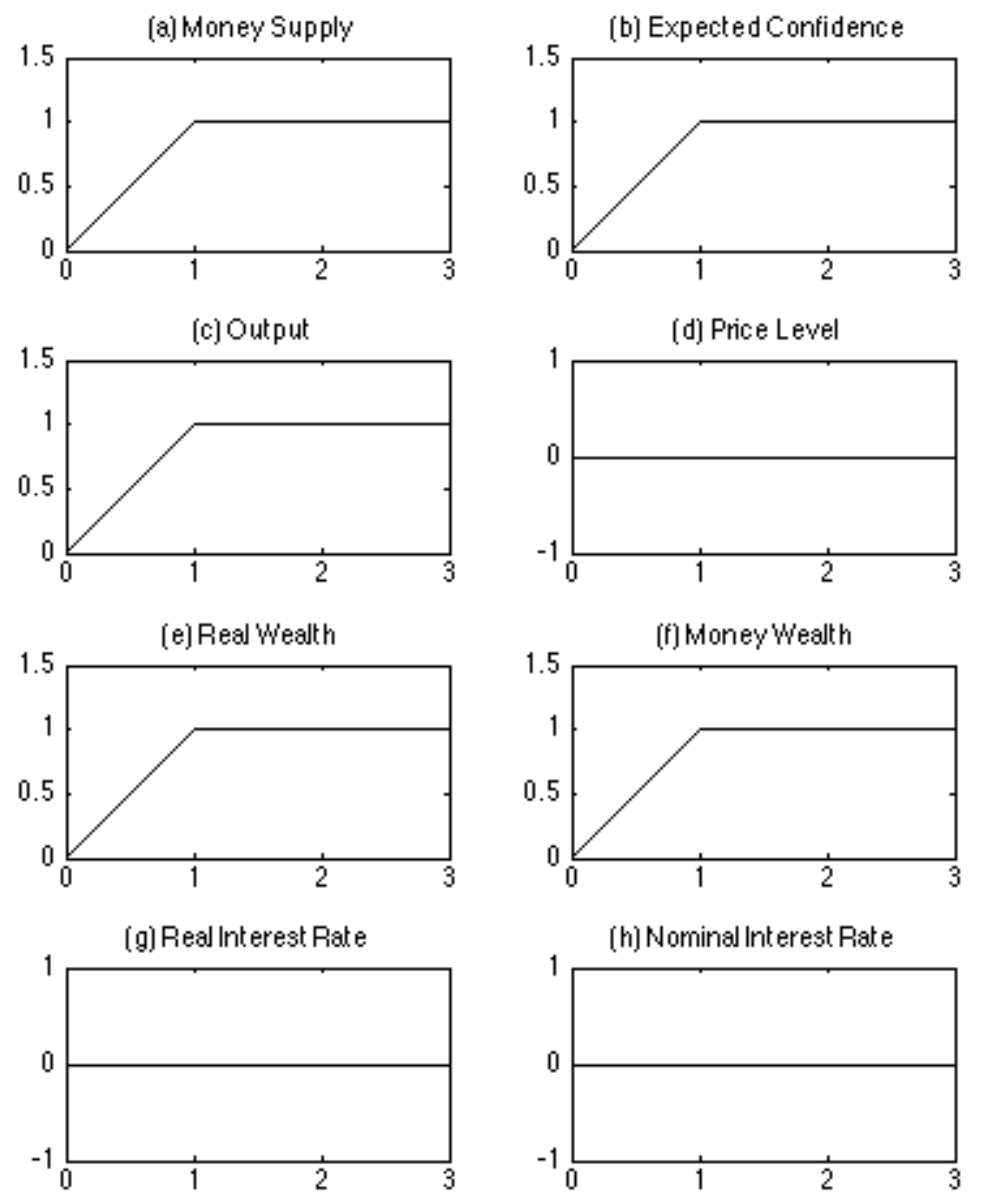

Figure 7. A Permanent Shock to the Supply of Money under Adaptive Beliefs

supply which is reflected entirely in changes to output and in the real value of financial assets.

\section{Conclusion}

We have proposed a fresh way of thinking about the monetary transmission mechanism. By integrating Keynesian economics with general equilibrium theory in a new way, we have provided an alternative to the IS-LM framework that we call the IS-LM-NAC model. Our new model provides an alternative narrative to New-Keynesian economics to explain how macroeconomic policy influences prices and employment.

Our approach differs from New Keynesian economics in two fundamental ways. First, our model displays dynamic indeterminacy. We focus on a dynamic path with predetermined prices to show that changes in the money supply may affect 
real economic activity even if all nominal prices are perfectly flexible. Second, our model displays steady state indeterminacy that arises as a consequence of search frictions in the labor market. We replace the classical search assumption that firms and workers bargain over the wage, with the Keynesian search assumption that beliefs about the future value of the stock market select a steady-state equilibrium. In our view, beliefs should be treated as a new fundamental of the model. The belief function advances our understanding of why the unemployment rate is so persistent in real world data.

Finally, we have presented a simple graphical apparatus that can be used by policy makers to understand how policy affects the economy. A new element, the NAC curve, connects the interest rate to current and expected future values of the stock market and it explains how 'animal spirits' influence economic activity. The IS-LM-NAC framework provides a rich new approach to policy analysis that explains the short-run and long-run effects of policy, without the assumption that prices are prevented from moving by artificial barriers to price adjustment.

\section{REFERENCES}

George A. Akerlof and Robert J. Shiller. Animal Spirits. Princeton University Press, Princeton and Oxford, 2009.

Jess Benhabib and Roger E. A. Farmer. The monetary transmission mechanism. Review of Economic Dynamics, 3(3):523-550, 2000.

Andreas Beyer and Roger E. A. Farmer. Natural rate doubts. Journal of Economic Dynamics and Control, 31(121):797-825, 2007.

Olivier J. Blanchard and Lawrence H. Summers. Hysteresis and the european unemployment problem. In Stanley Fischer, editor, NBER Macroeconomics Annual, volume 1, pages 15-90. National Bureau of Economic Research, Boston, MA, 1986.

Olivier J. Blanchard and Lawrence H. Summers. Hysteresis in unemployment. European Economic Review, 31:288-295, 1987.

Lawrence Christiano, Martin Eichenbaum, and Charles Evans. Nominal rigidities and the dynamics effects of a shock to monetary policy. Journal of Political Economy, 113(1):1-45, 2005.

Peter A. Diamond. Aggregate demand management in search equilibrium. Journal of Political Economy, 90:881-94, 1982.

George W. Evans and Seppo Honkapohja. Learning and Expectations in Macroeconomics. Princeton University Press, Princeton, 2001.

Roger E. A. Farmer. Sticky prices. Economic Journal,, 101(409):1369-1379, 1991. 
Roger E. A. Farmer. The Macroeconomics of Self-Fulfilling Prophecies. MIT Press, Cambridge, MA, 1993.

Roger E. A. Farmer. Two new keynesian theories of sticky prices. Macroeconomic Dynamics, 4(1):74-107, 2000.

Roger E. A. Farmer. Why does the data reject the lucas critique? Annales d'Economie et de Statistiques, 67/68:111-129, 2002.

Roger E. A. Farmer. How the Economy Works: Confidence, Crashes and Selffulfilling Prophecies. Oxford University Press, New York, April 2010a.

Roger E. A. Farmer. Expectations, Employment and Prices. Oxford University Press, New York, March 2010b.

Roger E. A. Farmer. Confidence, crashes and animal spirits. Economic Journal, 122(559), March 2012a.

Roger E. A. Farmer. The stock market crash of 2008 caused the great recession: Theory and evidence. Journal of Economic Dynamics and Control, 36:697-707, $2012 b$.

Roger E. A. Farmer. Animal spirits, persistent unemployment and the belief function. In Roman Frydman and Edmund S. Phelps, editors, Rethinking Expectations: The Way Forward for Macroeconomics, chapter 5, pages 251-276. Princeton University Press, Princeton, NJ, 2012c.

Roger E. A. Farmer. Animal spirits, financial crises and persistent unemployment. Economic Journal, 123(568):317-340, 2013.

Roger E. A. Farmer. The stock market crash really did cause the great recession. Oxford Bulletin of Economics and Statistics, 77(5):617-633, 2015.

Roger E. A. Farmer. Prosperity for All: How to Prevent Financial Crises. Oxford University Press, New York, September 2016a.

Roger E. A. Farmer. The evolution of endogenous business cycles. Macroeconomic Dynamics, 20:554-557, 2016b.

Roger E. A. Farmer and Giovanni Nicolò. Keynesian economics without the phillips curve. UCLA mimeo, June 2016.

Roger E A Farmer and Michael Woodford. Self-fulfilling prophecies and the business cycle. Caress Working Paper 84-12, 1984.

Roger E A Farmer and Michael Woodford. Self-fulfilling prophecies and the business cycle. Macroeconomic Dynamics, 1(4):740-769, 1997.

Milton Friedman. The role of monetary policy. American Economic Review, 58 (March):1-17, 1968. 
John Maynard Keynes. The General Theory of Employment, Interest and Money. MacMillan and Co., London and Basingstoke, 1936. 1973 edition published for the Royal Economic Society, Cambridge.

Robert G. King, Charles I. Plosser, James Stock, and Mark. Watson. Stochastic trends and economic fluctuations. American Economic Review, 81(4):819-840, 1991.

Peter J. Klenow and Benjamin A. Malin. Microeconomic evidence on price setting. In Benjamin M. Friedman and Michael Woodford, editors, Handbook of Monetary Economics, volume 3, pages 231-284. Elsevier, Amsterdam \& New York, 2017.

Gregory N. Mankiw. Small menu costs and large buiness cycles: A macroeconomic model of monopoly. QJE, 100:529-537, 1985.

N. Gregory Mankiw. Principles of Economics. Cengage, New York, 2015. Seventh Edition.

N. Gregory Mankiw and Ricardo Reis. Sticky information in general equilibrium. Journal of the European Economic Association, 5(2-3):603-613, 2007.

Kenneth Matheny. Non-neutral responses to money supply shocks when consumption and leisure are pareto substitutes. Economic Theory, 11:379-402, 1998.

Dale T. Mortensen. A theory of wage and employment dynamics. In Edmund S. Phelps, G. C. Archibald, and Armen A. Alchian, editors, Microeconomic Foundations of Employment and Inflation Theory. W. W. Norton, New York, 1970.

Don. Patinkin. Money Interest and Prices. The MIT Press, Cambridge, Massachusetts, second abridged edition, 1956.

C. A. Pissarides. Job search and participation. Economica, 43:333-349, 1976.

Dmitry Plotnikov. Three Essays on Macroeonomics with Incomplete Factor Markets. PhD thesis, UCLA, 2013.

Dmitry Plotnikov. Hysterisis in unemployment and jobless recoveries. IMF Working Paper Series, (77), May 2014.

Paul A. Samuelson. Economics: An Introductory Analysis (3rd Ed.). McGraw Hill, 1955.

Christopher A. Sims. Solving linear rational expectations models. Journal of Computational Economics, 20(1-2):1-20, 2001.

Christopher A. Sims. Implications of rational inattention. Journal of Monetary Economics, 50:665-690, 2003. 
Frank Smets and Raf Wouters. Shocks and frictions in U.S. business cycles: A Bayesian DSGE approach. American Economic Review, 97(3):586-606, June 2007.

Léon Walras. Elements of Pure Economics, 4th ed. 1926, rev ed. 1926, Engl transl. 2003. Routledge, New York, 1899. 